Acta PoÉTiCa $37 \cdot 2$

julio-diciembre

$2016(7-20)$

Daniella BLeJer

Universidad Iberoamericana

daniblejer@yahoo.com

\title{
Exploraciones de la amnesia colectiva en torno a la violencia de Estado en 2666
}

\section{Explorations of Collective Amnesia about State Violence in 2666}

Roberto Bolaño utiliza el desarrollo literario de la novela policial para conformar los principios de su poética. En la reelaboración del género se aproxima a sus normas, pero también las desacata porque si bien está interesado en la capacidad del género de mostrar el reflejo de la sociedad, su pregunta fundamental es literaria. El presente texto discute el doble movimiento en 2666 como mecanismo para problematizar la diseminación de la violencia sistémica pero también para replantear los debates del siglo xx en torno al arte.

PALABRAS CLAVE: Roberto Bolaño, 2666, género policial, desmemoria.

Roberto Bolaño uses the literary development of the detective novel in order to shape the principles of his poetics. The reconsideration of genre appeals to his norms but at the same time defies them, because, while he is interested in the ability of genre to show the reflection of society, his fundamental question is literary. This text discusses the double movement in 2666 as a mechanism used to problematize the spread of systemic violence, but also, to rethink twentieth-century debates about art.

KEYWORDS: Roberto Bolaño, 2666, crime fiction, failure of memory.

Fecha de recepción: 11 de octubre de 2015

Fecha de aceptación: 29 de enero de 2016 
$\mathrm{D}$ e forma desarticulada y fragmentaria, 2666 intenta relacionar distintas realidades de la sociedad contemporánea. Mediante un acercamiento irónico a la globalización, donde las fronteras que permanecen son la desigualdad y la injusticia, la obra de Roberto Bolaño plantea que junto con la homogeneización de la cultura, la violencia también se ha globalizado. De la Europa nazi y la Unión Soviética, a las dictaduras en Chile y Argentina, hasta los feminicidios de la frontera entre México y Estados Unidos, las problemáticas nacionales e históricas en la novela se diseminan y la violencia se expande.

La articulación de esta temática ocurre por medio del (des)engarzado de las cinco partes que conforman 2666: "La parte de los críticos", "La parte de Amalfitano", "La parte de Fate", "La parte de los crímenes" y "La parte de Archimboldi". Estas piezas actúan como narraciones independientes, incluso como novelas, vinculadas entre sí a través de diversos componentes que circulan de un relato a otro. El elemento que las mantiene conectadas es el espacio de Santa Teresa, la encarnación de Ciudad Juárez. La ciudad fronteriza envuelta en un feminicidio cruel y degradante ante el cual la policía y el Estado parecieran estar comprometidos actúa como una especie de agujero negro. Es en este espacio donde desaparece el enigmático escritor alemán que adopta el seudónimo de Benno Von Archimboldi. El mismo escenario donde los críticos europeos, en pos del escritor, parecieran asimilarse a la totalidad de la violencia fronteriza mediante un comportamiento indiferente y cínico ante la realidad que se depliega en la frontera. Santa Teresa es la última parada de una travesía hacia la disolución donde enloquece el profesor de filosofía y exilado chileno, Oscar Amalfitano, quien encarna al "letrado" latinoamericano de la segunda mitad del siglo veinte, desencantado con el mundo tras los golpes militares y el desmoronamiento de la izquierda. Es el centro gravitacional donde Fate, un periodista afroamericano de Harlem, presenciará la disolución del Estado y del tejido social. La ciudad fronteriza sometida a la lucha de narcotraficantes, policías, judiciales, políticos, banqueros, redes de prostitución en 
un contexto de economía de maquila, es el espacio donde desaparecen cientos de mujeres todos los años.

A pesar de la relativa autonomía de estas partes, la comprensión de su sistema de signos y la apreciación de su riqueza sólo se completa mediante la lectura de la totalidad de la obra, por lo que es inevitable preguntar sobre la estructura en partes en lugar de capítulos. Dejando a un lado las especulaciones en torno a la condición póstuma de la novela, ${ }^{1}$ encontramos la respuesta dentro del mismo texto a través del Testamento geométrico, ${ }^{2}$ un libro encontrado entre las cajas de Amalfitano traídas de Barcelona y que, a la manera de Duchamp en su Readymade infeliz (1918), deja colgado a la intemperie para que aprenda cosas de la vida real. El libro de Dieste o Testamento geométrico forma parte de las obsesiones con las que Amalfitano se abstrae de la realidad y funciona como una especie de catalejo que le permite aproximarse a su entorno:

Cuando llegaron a casa ya no había luz pero la sombra del libro de Dieste que colgaba del tendedero era más clara, más fija, más razonable, pensó Amalfitano, que todo lo que había visto en el extrarradio de Santa Teresa y en la misma ciudad, imágenes sin asidero, imágenes que contenían en sí toda la orfandad del mundo, fragmentos, fragmentos (Bolaño: 265).

${ }^{1}$ Roberto Bolaño murió de una insuficiencia hepática, por lo que dejó inconcluso el final de la última parte de 2666. Como es sabido, el texto fue entregado al amigo y crítico literario conocedor de su obra, Ignacio Echeverría, a quien el autor nombró albacea. El paratexto de 2666, "Nota de los herederos del autor", explica la voluntad de Bolaño: publicar cinco libros, uno por cada parte de la novela, con el fin de facilitar su comercialización y dejar una sucesión favorable a su viuda e hijos. Los herederos, en conjunto con Ignacio Echeverría y Jorge Herralde, decidieron respetar el valor literario de la obra y publicarla íntegra, en un mismo libro, tal y como Bolaño lo hubiese deseado de no haber interferido la preocupación por el futuro económico de su familia.

${ }^{2}$ El Testamento geométrico, como después se aclara en 2666 mediante la inserción de un texto del historiador del arte Thomas Calvin Tomkins, está ligado al Ready-made infeliz o Ready-made malheureux que concibiera Marcel Duchamp en Buenos Aires como regalo de boda para su hermana Suzanne y su cuñado y amigo Jean Crotti. Desde Buenos Aires. Duchamp envió instrucciones por carta a la pareja instalada en París: colgar un libro de geometría de una cuerda en el balcón del departamento, de modo que el viento pudiera "elegir sus problemas, pasar las páginas e incluso arrancarlas". La pareja cumple las instrucciones y monta el libro en el cordel, después Suzanne lo fotografía y pinta una obra: Le ready-made malheureux de Marcel Duchamp. 
La cita pareciera afirmar el poder del arte para comprender el mundo. La reformulación del Ready-Made funciona como metáfora de 2666 de manera más directa: "En la solapa se advertía que aquel Testamento geométrico eran en realidad tres libros, 'con su propia unidad, pero funcionalmente correlacionados por el destino del conjunto"' (240). En este sentido, el libro es la metáfora de 2666 que ofrece claves sobre cómo leer la novela. El elemento autorreferencial ayuda a esclarecer la interrogante y a comprender la intención del autor implícito: problematizar la unidad de la composición artística mediante una macroestructura.

La macroestructura facilita la capacidad de la obra de sintetizar en ella otros lenguajes y géneros discursivos que se mezclan, se adulteran y también son impugnados; algunos de ellos se presentan de manera contundente, mientras que otros aparecen en forma de breves marcas textuales, por ejemplo: la novela policial y sus diversas variantes (el policial clásico, la serie negra y el neopolicial latinoamericano), la novela de crecimiento, el diario, la novela de ciencia ficción, la novela pornográfica, la novela enciclopédica, la hipernovela, el archivo de expedientes policiales-forenses, el género apocalíptico y las crónicas de guerra. La heterogeneidad genérica logra establecer un contacto con el mundo real y contrarrestar el efecto producido por la percepción de un mundo fragmentado e inestable. Sin embargo, es el género policial el que predomina en la novela debido a su función de "puente" entre una estética realista y otra vanguardista.

Se trata de un género que incuba dentro de sí una vasta relación con otros, no sólo por los arcaísmos inscritos en su memoria creativa a partir de su origen, desarrollo y diversas reactualizaciones, sino por la impronta de la realidad que contribuye al ingreso de diversas glosas y estratos sociales, a la problematización de otros campos del orden jurídico y a la tendencia a absorber nuevos géneros producidos por los avances tecnológicos y otros géneros populares a través del vínculo que guarda con la cultura de masas. Particularmente, el género policial en su versión contemporánea produce una pregunta ético-política acerca de la naturaleza humana, ¿por qué se comete un crimen?, cuestionamiento que conduce a la revisión de la sociedad donde se inscribe. 
El género policial en 2666 tiene un papel central en la coordinación, organización y cohesión de la serie de recursos y estrategias narrativas planteadas por la macroestructura. Esta función modelizadora (Lotman: 17-46) es puesta en tensión con lo inconexo, la inestabilidad, lo múltiple y lo mutable que palpita en los materiales de significación narrativa. Empezando por el narrador, quien a pesar de ser el mismo en las cinco partes, no produce estabilidad porque transmite la información de forma ambigua, como si no estuviera seguro de lo que observa. En "La parte de los crímenes", por ejemplo, o el reporte policial/forense de cuerpos de mujeres encontrados en el desierto fronterizo entre 1993 y $1997,{ }^{3}$ el tono dubitativo da cuenta de las imprecisiones del archivo:

Esto ocurrió en 1993. En enero de 1993. A partir de esta muerta comenzaron a contarse los asesinatos de mujeres. Pero es probable que antes hubiera otras. La primera muerta se llamaba Esperanza Gómez Saldaña y tenía trece años. Pero es probable que no fuera la primera muerta. Tal vez por comodidad, por ser la primera asesinada en el año 1993, ella encabeza la lista. Aunque seguramente en 1992 murieron otras. Otras que quedaron fuera de la lista o que jamás nadie las encontró, enterradas en fosas comunes en el desierto o esparcidas sus cenizas en medio de la noche, cuando ni el que siembra sabe en dónde, en qué lugar se encuentra (Bolaño: 444).

Este tono se sostiene y se multiplica en cada uno de los expedientes para crear una crisis de sentido y dar cuenta de la incapacidad del archivo de ser un reflejo de la realidad. Es una de las maneras más potentes para problematizar la pérdida de la memoria histórica y la memoria inmediata.

Por otro lado, las historias de las cinco partes que de por sí fragmentan la totalidad del relato, a su vez se bifurcan en diversas subhistorias. En "La parte de los crímenes", por ejemplo, la narración de los expedientes ocurre en orden cronológico y yuxtapuesto a una multiplicidad de historias que en la medida en que permanecen inconclusas, se van ramificando sucesivamente. Este modelo establece un estrecho entra-

${ }^{3}$ Bolaño se basó en la investigación del periodista Sergio González, Huesos en el desierto (2002) para configurar esta parte. 
mado con los expedientes, de tal modo que en el momento en que pareciera establecerse un patrón en el modus operandi de los crímenes, los registros de las prácticas asesinas cambian, sugiriendo diversos móviles, desde la filmación de películas porno o snuff, el efecto de las fiestas salvajes de los narcotraficantes, hasta el abuso cotidiano del machismo producto de una misoginia arrolladora y generalizada. Se trata de un modelo de red de relaciones donde la multiplicidad de contenidos desborda los límites de la representación o los límites de la comprensión del lector. No obstante, en la supuesta cronología de los expedientes, todos los acontecimientos narrados aparentan un tiempo horizontal, una especie de simultaneidad cuyo resultado es la nulificación del pasado, como si el único tiempo existente en la narración fuera el eterno presente. El efecto en el lector de la simultaneidad del presente es la imposibilidad de recordar, ya no digamos asimilar, los hechos. Este tipo de efecto es similar a la dinámica producida por los periódicos y los noticieros televisivos, incrementada mediante la multiplicidad y la velocidad de la información ofrecida por internet. Desde esta perspectiva los expedientes forenses no activan una memoria o un homenaje, sino que provocan la pérdida, en el mar de los acontecimientos, de la relevancia de cada homicidio.

Aunado a esto, las dimensiones espacio-temporales se constriñen y se expanden para producir el borramiento de sus fronteras. Al interior de 2666 la imagen cronotópica de Santa Teresa se construye mediante el proceso de asimilación de un tiempo histórico regido por los ciclos de violencia y olvido, de modo que en la novela esta ciudad es la materialización de Ciudad Juárez, pero también es la España postfranquista y la Europa nazi, la Rusia de Stalin y el Chile de los pactos de la transición. La novela de Bolaño se teje alrededor de una multiplicidad de dimensiones espacio-temporales cuyo epicentro, Santa Teresa, emite la repetición de los sucesos de un quiebre epocal a otro, de una forma de violencia de Estado a otra, como si la historia estuviera condenada a repetirse. Un ejemplo entre otros ocurre a partir de Lola, la esposa de Amalfitano, quien encarna "la movida", esa generación perdida en un limbo de drogas y sexo que pagó el precio del olvido con su propia locura. Lola contrae sida: la aparición de la enfermedad tiene el propósito, sobre todo, de vincular la condición infecciosa del sida a la 
locura. Dentro del relato, ambas enfermedades pueden ser leídas como producto del olvido y de la negación, ambas se contagian de un organismo a otro y se transfieren de una coordenada espacio-temporal a otra totalmente remota. A través de Lola, la locura se traslada de España a México, argumento que Amalfitano constata al evocar a la mujer desde su casa en la ciudad fronteriza: "La locura es contagiosa, pensó Amalfitano sentado en el suelo del porche de su casa mientras el cielo se cerraba de repente y ya no se podía ver la luna ni las estrellas ni las luces errantes que es fama que se observan, sin necesidad de catalejos ni telescopios, en aquella zona del norte de Sonora y el sur de Arizona" (228-229).

Si bien la locura por contagio opera como vehículo para dispersar el Mal en 2666, en el inestable mundo narrado, los personajes se ven sujetos a la fatalidad/voluntariedad del viaje como pérdida de la razón, de ahí su imposibilidad para distinguir entre sueño y vigilia, realidad o delirio. El personaje Fate, por ejemplo, cuya identidad estaba bien definida en Nueva York, padece de una serie de inestabilidades al llegar a la frontera en donde el paso de un lado al otro es inmediato. La pérdida o dislocación de su identidad pareciera producir nuevos desequilibrios, esta vez vinculados con el sentido del tiempo. La noción temporal de Fate se distorsiona al escuchar un comentario racista sobre un boxeador mexicano, seguido de risas burlonas y luego de una falsa solemnidad: "Los rostros, repentinamente serios, provocaron en Fate la sensación de un baile de máscaras. Por un brevísimo instante le faltó el aire, vio el piso vacío de su madre, tuvo la premonición de dos personas haciendo el amor en una habitación que daba pena, todo al mismo tiempo, un tiempo definido por la palabra climatérico" (366).

La visión apocalíptica del tiempo-espacio que atrae a estos personajes se logra mediante el uso de la lógica del género policial. El mismo título, que anuncia el espacio distópico ubicado en el presente, da cuenta de la relación. La clave para decodificar el título se encuentra en el Apocalipsis de San Juan, capítulo 13:18, que versa: “Aquí hay sabiduría. El que tiene entendimiento cuente el número de la bestia, pues es número de hombre. Y su número es seiscientos sesenta y seis" (Santa Biblia). Decir que "el número de la Bestia" es "el número de un hombre" implica un nombre (el del hombre que será el Anticristo) cuyo 
valor numérico es 666, leído "seiscientos sesenta y seis". El enigma se resuelve a partir del método basado en el desciframiento e interpretación de las escrituras conocido como gematría, una de las variedades de la cábala donde el alfabeto hebreo se considera un reflejo matemático del mundo en el cual existe un valor numérico para cada letra. ${ }^{4}$

Este tipo de ejercicio hermenéutico se asemeja a la formulación de Roland Barthes en $S / Z$, donde la búsqueda de la "verdad" textual y su cometido central es "articular, de diversas maneras, una pregunta, su respuesta y los variados accidentes que pueden preparar la pregunta o retrasar la respuesta, o también formular un enigma y llevar a su desciframiento" (12). Mediante un código hermenéutico, el autor enganchará a su lector en un juego de interpretaciones que convoca al método de la exégesis para extraer el significado del texto. Algo similar plantea José F. Colmeiro en La novela policiaca española: teoría e historia crítica: "El tipo de interés que genera el código hermenéutico en la novela policiaca no se debe a una particular estructura sintáctica o a un simple desarrollo temático; su interés reside en la intriga no como enredo meramente casual o argumental de la historia, sino la intriga que a lo largo del discurso origina la calculada manipulación informativa por parte del narrador" (78-79).

Desde esta perspectiva, la trama de 2666 en su totalidad plantea dos enigmas fundamentales cuyo develamiento será manipulado por el narrador a lo largo de la novela: el primero se refiere a la identidad del escritor Benno von Archimboldi; el segundo, a la identidad del asesino responsable de los crímenes de Santa Teresa.

La diferencia entre estas incógnitas pone en evidencia la existencia de los géneros internos de la novela, pues ellas implican formas distintas de narrar que corresponden a distintas "especies" del género policial según la formulación de Todorov en "Tipología de la novela policial". El primer misterio, el paradero de Archimboldi, al igual que la novela

${ }^{4}$ Según la lógica de la gematría, cada palabra tiene un valor numérico resultante de la suma de los valores de cada una de sus letras y las palabras con el mismo valor son equivalentes e intercambiables. Basados en este último parámetro, muchos han intentado interpretar el Apocalipsis a través de la sustitución de palabras de igual valor para obtener frases con mensajes ocultos. 
clásica policial o "novela enigma", ${ }^{5}$ contiene dos historias: la de una desaparición y la de la investigación de esa desaparición. A diferencia del policial clásico, en 2666 el orden ha sido invertido, de tal forma que primero se relata la historia de la investigación de la desaparición de Archimboldi y posteriormente se devela aquella en torno a su desaparición.

El segundo enigma, la autoría de los crímenes cometidos contra mujeres de Santa Teresa, se inscribe en la llamada novela negra, ${ }^{6}$ la que de acuerdo a Todorov, "fusiona las dos historias o, dicho de otro modo, suprime la primera y da existencia a la segunda" (37). Así, los crímenes de Santa Teresa no son presentados en forma de memoria, es decir, no hay un antes de los crímenes, sino que éstos sólo son narrados en prospección. De la reelaboración y el cruce de las dos estructuras (el policial clásico y la serie negra) y de ambos enigmas (la identidad de Archimboldi y la identidad del asesino de mujeres en Santa Teresa), se desprenden claves para comprender la violencia y el exterminio masivo en sus formas contemporáneas.

La omisión de datos sobre la identidad de Archimboldi y sus motivos para viajar a Santa Teresa, generará suspenso a todo lo largo de la primera parte, titulada "La parte de los críticos". Una vez terminada, el lector no volverá a saber nada acerca del escritor alemán hasta la última parte. Sin embargo, la pregunta acerca de su identidad se desplaza, mediante diversas estrategias narrativas, hacia la inquietud por descifrar la

${ }^{5}$ La novela policial clásica o "novela de enigma" se origina en la Inglaterra victoriana donde los éxodos del campo a la ciudad industrializada produjeron una variación de sensibilidades: aquellas regidas por la razón y la ciencia, y, en un sentido opuesto, las que buscaban el sentido místico de la fe, la subjetividad y el ensueño. En este cruce de tensiones heterogéneas, el policial introduce personajes y ambientes enteramente urbanos (la policía, los criminales, el detective) para plantear un enigma que debe ser resuelto por medio de la lógica. Los crímenes de la calle Morgue de Edgar Allan Poe, se considera la obra que acuñó al género. Desde sus inicios, el género gozó de gran popularidad y difusión con autores como Sir Arthur Conan Doyle y Chesterton y, posteriormente, durante el periodo de entre de guerras con Agatha Christie.

${ }^{6}$ La novela negra es un género creado en los Estados Unidos poco antes y, sobre todo, después de la Segunda Guerra Mundial. Según Javier Coma, la novela negra surge a partir del interés y enfoque realista de la temática criminal de los años veinte, los años de la prohibición. Gracias a su relación inmediata con la realidad social, la destreza de los escritores — entre ellos William Riley Burnett, Dashiel Hammet, Donald Henderson Clarke, James M. Cain, William Irish y Raymond Chandler-, y un lenguaje sustentado en la gestualidad y los diálogos inicia una intensa colaboración con Hollywood. 
identidad del asesino de mujeres de la ciudad fronteriza que plantean las partes centrales de la novela. El primer vínculo, en este sentido, ocurre al inicio de "La parte de los críticos" a través de un pequeño guiño: durante sus investigaciones, los críticos conocen a un escritor quien conoció a Archimboldi en la juventud y que recordaba la chaqueta con la cual este último acostumbraba vestirse: "la chaqueta [...] era inolvidable, una chaqueta de cuero negro, con el cuello alto [...] bolsillos horizontales a cada lado, y una hilera de cuatro botones cosidos como con hilo de pescar [...] una chaqueta que evocaba, no sé por qué, a las que usaban algunos policías de la Gestapo" (Bolaño: 35).

La referencia a la SS es inquietante y siembra en el lector una sospecha: el escritor alemán oculta un secreto sombrío, quizás un pasado nazi. El desplazamiento de identidades es el primero de varios recursos mediante los cuales la novela plantea el desplazamiento de la violencia de la Europa nazi a uno de los lugares más emblemáticos de la economía global: el límite entre Estados Unidos y México, donde en un lado de la frontera las industrias maquiladoras pagan sueldos ínfimos y del otro lado se surten de bienes de consumo a precios irrisorios.

No se trata de una comparación entre los totalitarismos europeos, las dictaduras del Cono Sur y el sistema económico global, sino que el desplazamiento hace énfasis en la necesidad de atender esta violencia que también se muestra extrema y sistémica. Recordemos que en el año en que se publicó 2666, poco se sabía sobre las muertas de Juárez, la población aún desconocía el grado de influencia que tenían los cárteles de droga en las instancias políticas y públicas, y aún se ignoraban a fondo las consecuencias del Tratado de Libre Comercio. El primero en señalar que Ciudad Juárez se había convertido en el laboratorio de la globalización neoliberal fue Charles Bowden en Juárez, the laboratory of our future (1998). Más adelante, dos periodistas mexicanos publicarían investigaciones sobre el tema poniendo en riesgo su propio pellejo; Victor Ronquillo, Las muertas de Juárez: Crónica de una larga pesadilla (1999) y Sergio González, Huesos en el desierto (2002). Bolaño se ocupa del tema por el interés que tiene (y que muestra a lo largo de todo su proyecto literario) en el problema de la amnesia colectiva en torno a la violencia de Estado. 
La denuncia al sistema que produce las condiciones de la violencia vincula a la trama de 2666 con otra especie del género policial, el "neopolicial latinoamericano". Según Rosi Song, el término neopolicial fue acuñado por el mexicano Paco Ignacio Taibo II para distinguir la versión crítica y latinoamericana de la novela negra. Si bien el neopolicial retoma de la serie negra el lenguaje violento y el realismo "como medio para expresar temas políticos y sociales como el de la represión y la violencia institucionalizada" (Song: 90), esta especie del género tiene un distintivo: incluye en sus tramas asesinos no identificables, representantes de múltiples sectores de la sociedad: policías, jueces, políticos y personajes asociados con los medios que delatan la descomposición del sistema del Estado. La novedad en 2666 es que la denuncia trasciende las fronteras locales para ser colocada en un contexto global. En este sentido, el autor no sólo hace un acercamiento a la estructura del Estado como promotor de la ilegalidad y del crimen, sino al sistema global que rige la economía.

Si bien Bolaño usa algunas de las estrategias de la novela policial, el detective en su obra, por lo general, es un crítico o un filólogo en pos de un escritor y el significado de su obra. En este sentido, el uso de la lógica para solucionar un crimen no sólo sirve para desenmascarar el rostro del asesino, sino también para experimentar, dialogar y cuestionar formas de hacer literatura. La preocupación por construir una memoria colectiva y narrar el horror del destino latinoamericano en toda su crudeza viene de la mano de una apuesta estética vinculada a la vocación de mezclar géneros, de experimentar con formas que no son ni novela ni ensayo ni poesía; de jugar a borrar las fronteras entre la ficción y la no-ficción.

Bolaño abre su obra a la diferencia, a la marginación, al mundo de la heteroglosia social donde la interacción entre géneros, su estilización paródica y la intención de interferir tradiciones, no sólo ocurre con el fin de minar los géneros canónicos; se trata de mostrar el universo del género literario como campo de modificación permanente que permite la creación de una literatura híbrida, compleja, cuyo cruce de tensiones y contradicciones se convierte en el espacio desde el cual sea posible leer la realidad. En 2666 hay diversas alusiones a la ciencia ficción, al llamado cine Clase B y a la pornografía. La imagen más potente com- 
puesta por elementos de los tres géneros mencionados la conforma "la máquina de movimiento perpetuo", metáfora de la economía global sintetizada en una película pornográfica que irrumpe en la trama de "La parte de Fate". Se trata de un filme de bajo presupuesto y con actores desconocidos realizado en Santa Teresa por Robert Rodríguez, antes de que este director se volviera famoso:

Aparecía una mujer joven, muy morena, delgada y con grandes pechos, que se desnudaba sentada en una cama. De la oscuridad surgían tres tipos que primero le hablaban al oído y luego la follaban. Al principio la mujer oponía resistencia. Miraba directamente a la cámara y decía algo en español que Fate no entendía. Luego, fingía un orgasmo y se ponía a gritar. Entonces los tipos, que hasta ese momento la estaban poseyendo alternativamente, se acoplaban a la vez, el primero la penetraba por la vagina, el segundo por el ano y el tercero metía su verga en la boca de la mujer. El cuadro que formaban era el de una máquina de movimiento continuo. El espectador adivinaba que la máquina iba a estallar en algún momento, pero la forma del estallido, y cuándo ocurriría, era imprevisible. Y entonces la mujer se corría de verdad. Un orgasmo que no estaba previsto y que ella era la que menos esperaba. Los movimientos de la mujer, constreñidos por el peso de los tres tipos, se aceleraron. Sus ojos, fijos en la cámara, que a su vez se acercó a su rostro, decían algo aunque en un lenguaje inidentificable. Por un instante toda ella pareció brillar [...] Luego la carne pareció desprenderse de sus huesos y caer al suelo de aquel burdel anónimo [...] dejando un esqueleto [...] sin ojos, sin labios, una calavera que de improviso empezó a reírse de todo (405-406).

La máquina de movimiento perpetuo es una construcción imposible imaginada por el hombre desde la antigüedad hasta mediados del siglo XIX (cuando también se planteó la primera ley de la termodinámica que contradice su principio). Se trata de un dispositivo que realiza trabajo continuo sin la necesidad de una energía externa que la impulse. Si bien la noción de esta máquina se inspira en la naturaleza, el deseo de convertir de manera espontánea energía térmica en trabajo mecánico estriba en la posibilidad de acumular riquezas mediante la explotación de una fuerza de trabajo inimaginablemente barata (en Ord-Hume). Bolaño logra la construcción de una metáfora potente de la economía 
global mediante el cruce de tres géneros marginados como el cine $\mathrm{B}$, la pornografía y la ciencia ficción: una muestra de la capacidad de estos géneros de captar lo más sórdido y perverso de la realidad.

La novela híbrida de Bolaño problematiza estas tensiones estéticas y plantea un encuentro. No se trata de proponer un retorno al realismo ni de negar la vanguardia, mucho menos de intentar ajustar diferencias irreconciliables, sino de lograr la coexistencia entre estéticas contradictorias que puedan ser leídas desde distintas ópticas, de allí la interferencia del pintor italiano Arcimboldo y sus juegos y paradojas visuales. Son estas diferencias las que producen una diversidad, que si bien no libran a la novela de su comercialización masiva, sí la salvan de su mediatización.

La diversidad se logra por medio del género policial, cuya conexión con la glosa de los diversos estratos sociales y profesionales tiende puentes entre la ambición de iluminar una realidad y la de encarnar la percepción fragmentada y subjetiva, entre la estética que forma parte de la cultura popular y la sofisticada estética vanguardista, entre el mundo que refleja la literatura y aquél que proyectan los medios de comunicación masiva, entre la inserción de la obra literaria a la industria cultural y la posibilidad de ubicarse en un horizonte ético.

BIBLIOGRAFÍA

BAJTín, M. M. "Las formas del tiempo y del cronotopo en la novela", en Teoría y estética de la novela. Trad. Tatiana Bubnova. Madrid: Taurus, 1989.

BAJTín, M. M. "El problema de los géneros", en Estética de la creación verbal. Trad. Tatiana Bubnova. México: Siglo XXI, 2005.

Barthes, Roland. S/Z. Trad. Nicolás Rosa. México: Siglo XXI, 1987.

Bolaño, Roberto. 2666. Barcelona: Anagrama, 2004.

Bowden, Charles. Juárez, the laboratory of our future. New York: Aperture, 1998.

Colmeiro, José F. La novela policiaca española: teoría e historia crítica. Barcelona: Anthropos, 1994.

Coma, Javier. Diccionario del cine negro. Barcelona: Plaza Janés, 1990.

Lotman, Yuri M. "Arte y lenguaje”, en Estructura del texto artístico. Madrid: Itsmo, 1982:17-46. 
Ord-Hume, Arthur W. J. G. Perpetual Motion: The History of an Obsession. New York: St. Martin's Press, 1977.

Santa Biblia. Versión Reina Valera 1960. Web. 12/10/15.

Song, H. Rosi. "El neopolicial de Paco Ignacio Taibo II: ¿Una resolución de la historia?”, en Hispamérica (2003): 91-96.Web. 12/12/15.

Todorov, Tzvetan. "Tipología de la novela policial", en El juego de los cautos. Daniel Link (comp.). Buenos Aires: La Marca, 200

\section{DANIELla BLEJER}

Doctora en letras por la Universidad Nacional Autónoma de México. Obtuvo mención honorífica con la tesis doctoral "La problematización de los géneros discursivos en 2666 de Roberto Bolaño". Realizó una estancia posdoctoral en la Universidad Iberoamericana donde concluyó la investigación "Los juegos de la intermedialidad en la cartografía de Roberto Bolaño", la cual se encuentra en proceso de publicación. Actualmente es docente en la Licenciatura en Literatura Latinoamericana y el Posgrado en Letras Modernas de la Universidad Iberoamericana. Su línea de investigación es: "Mapas, derivas y constelaciones en la literatura contemporánea". Blejer tiene varios artículos sobre literatura publicados en revistas especializadas, entre ellos "Las reencarnaciones de Santa Teresa de Jesús en 2666, de Roberto Bolaño" en la Revista de literatura mexicana contemporánea. 